\title{
An exploration of meaning accompanying active and passive touch without object contact
}

\author{
GLEN M. VAUGHT, State University of \\ New York, College at Oswego, Oswego, N.Y. \\ 13126
}

An attempt was made to demonstrate that movement accompanying the act of touch, as viewed in active and passive touch, contributes to "meaning" derived from that sense mode. Semantic differential ratings of active and passive touch in the absence of object contact supported the above assumption

J. J. Gibson (1966, p. 123) has noted that "active exploratory touch permits both the grasping of an object and a grasp of its meaning." In the next sentence, Gibson stated that "one may lay hold of the surroundings merely to obtain information." He did not, however, indicate whether or not passive touch resulted in similar degrees of information and/or meaning. It is assumed that Gibson's concept of "meaning" is more in keeping with what is usually termed denotative meaning, i.e., information (meaning) about an object is obtained from its stimulus characteristics such as texture, edges, rigidity, and the like. There is little doubt that Gibson's position is both reasonable and valid as far as stimulus properties of objects are concerned; however, this view may not account for the total act of perception, and it certainly does not provide a means of conceptualizing "representational processes" within Ss (Scagnelli, 1969). For example, since the complete act of perceiving via touch involves feedback from muscles and joints, it would seem reasonable to assume that such feedback somehow contributes to any determination of meaning but not denotative meaning. This part of the perceptual act, i.e., movement accompanying the act of touch, is thought to yield meaning that is more akin to "connotative" meaning since it does not come from the properties of the object being touched.

The present experiment sought to provide measures of meaning accompanying postural movement for both active and passive touch without object contact. Since active and passive touch differ in terms of the amount of body movement involved, and since this movement may somehow provide meaning for $S$, the distinction between active and passive touch should permit the observance of differences in meaning accompanying each of the modes. If, on the other hand, movement accompanying active and passive touch does not contribute to meaning, it would be expected that no measurable differences would exist between these two modes of touching.

\section{SUBJECTS}

The Ss were 35 male and 35 female $(\mathrm{N}=70)$ introductory psychology students whose course requirement included participation in two experiments per semester.

\section{MATERIALS}

The semantic differential of Osgood, Suci, \& Tannenbaum (1957) was employed to measure the connotative meaning accompanying the act of active-passive touch. The evaluative, activity, and potency scales were used with the following adjective pairs: evaluative-good-bad, clean-dirty, nice-awful, pleasant-unpleasant, fair-unfair, valuable-worthless, happy-sad honest-dishonest, beautiful-ugly activity-active-passive, fast-slow, hot-cold sharp-dull; potency-strong-weak, large-small, hard-soft, heavy-light, nugged-delicate. All adjective pairs were chosen on the basis of their high factor loadings. The mean rating for each of the three scales was determined for each $S$ and constituted the response measure.

\section{PROCEDURE}

Subjects signed-up for an experiment in perception on 1 of 2 days, with approximately equal numbers assigned to the two sessions. All Ss were instructed in the use of the semantic differential prior to the actual experiment. E showed Ss a simple Masonite form that had been used by $E$ in previous tactual form-discrimination experiments. For the active-touch condition, $E$ asked $S s$ to imagine that they were actively feeling the form that they had previously viewed. Each $S$ was required to go through the motions of reaching and touching. In passive touch, Ss were required to place their hands on the arm rest of their chairs with their palms up, and to imagine the form being placed in their hands without movement of any kind. At no time during the experiment did any of the Ss actually touch the form, nor did they see the form beyond the brief instructional period. After each touch condition, Ss were told to rate the act of touch on the semantic differential.

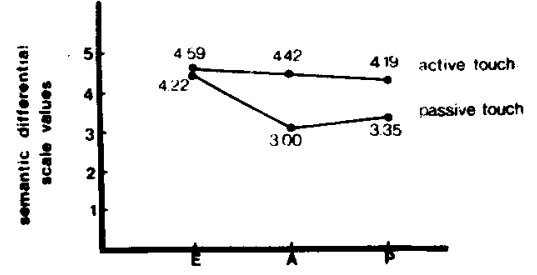

Fig. 1. Semantic differential scale vahues for the two modes of touch without object contact.

\section{RESULTS AND DISCUSSION}

An analysis of variance was performed on the SD ratings after Winer (1962, p. 327). Sex of the $S$ did not influence the ratings nor did it enter into the interactions. A significant difference was obtained for the overall mean rating of 4.36 for active touch and the passive-touch mean of 3.51 $(\mathrm{p}<.01)$. The SD-scale main effect was also statistically significant $(p<.01)$. The evaluative-scale mean of 4.40 differed from both the activity-scale mean of 3.71 and the potency-scale mean of $3.77(p<.01)$. The activity mean did not differ from the potency mean. Figure 1 shows the significant interaction between active-passive touch and the three SD scales $(p<.01)$. As can be seen, active touch was differentiated from passive touch in two of the three SD scales. This is clearly the most important finding of this study, since it is supportive of the notion that movement accompanying these two modes of touch will be reflected in Ss' SD ratings in a differential manner.

The overall findings of this exploratory study provide some insight into how meaning is gleaned through movement accompanying touch. Furthermore, since such meaning is independent of actually touching an object, it must come from something other than object qualities. For this reason, movement associated with the act of touch is thought to have meaning for Ss and is roughly analogous to the information value inherent in that which is touched. Whether or not the connotative-denotative distinction is appropriate for this kind of theorizing is certainly open to question; however, at this time, there are few metaphors available to the interested investigator.

\section{REFERENCES}

GIBSON, J. J. The senses considered as perceptual systems. Boston: Houghton Mifflin, 1966.

OSGOOD, C. E., SUCI, G. J., \& TANNENBAUM, P. H. The measurement of meaning. Urbana, Ill: University of Illinois Press, 1957.

SCAGNELLI, P. Relationships among visual imagery, language and haptics in spatial perception. Unpublished doctoral dissertation, Duke University, 1969.

WINER, B. J.Statistical principles in experimental design. New York: McGraw-Hill, 1962. 